\title{
Modeling projects interdependencies to measure their synergic impacts on a project portfolio
}

\author{
Mohammad Mahdi Nabati ${ }^{\mathrm{a}}$ and Maryam Ashrafi ${ }^{\mathrm{a}}$
}

${ }^{a}$ Department of Industrial Engineering and Management Systems, Amirkabir University of Technology (Tehran Polytechnic), Tehran, Iran

\section{H R O N I C L E}

\section{Article history:}

Received: July 5, 2020

Received in revised format:

February 18, 2021

Accepted: February 21, 2021

Available online:

February 21, 2021

Keywords:

Project Interdependencies

Project Portfolio Selection

Resources Interdependency

Knowledge Interdependency

Technical Interdependency

\section{A B S T R A C T}

One of the most critical factors used to evaluate the efficiency of the portfolio selection process is the ability of the model to measure interdependencies among projects. Varieties of interactions among projects lead to several kinds of synergies in the whole portfolio, such as resources and knowledge interdependencies. There are few studies focused on project portfolio selection accompanied by modeling and estimating the impact of synergies between projects. Hence, this paper presents a model to select the best project portfolio applying a particular model to measure the effects of several types of interdependencies between paired projects. Then, the Promethee II method is used to prioritize projects. Then, the portfolio selection model, which is a non-linear integer model, is solved to find the best set of projects. Finally, numerical examples are addressed to illustrate the method results and validity.

\section{Introduction}

Trends in project management reveal that project-based organizations are the norm in the future. It leads many organizations to establish a project portfolio management process to ensure a set of effective projects aligning with their strategies. However, in many organizations, the number of candidate projects to support organization strategies are significantly more than the available resources of the organization. Therefore, the development and implementation of a portfolio management system is a critical operational need to ensure the alignment of the resource allocation process with organization strategies and help organizations execute the most effective projects based on managerial criteria (Bathallath, Smedberg, \& Kjellin, 2016). The real-world process of project portfolio selection involves the evaluation of a set of candidate projects that may affect each other to select the most effective projects. Considering interdependencies between projects, we may expect benefit or return from projects, which is more than the sum of their standalone effects because of the synergies of projects in a portfolio. For instance, the simultaneous implementation of ISO 9001 and ISO 14001 systems causes the total number of required activities to be reduced in comparison with the separate executions of the two aforementioned projects. Because the identification and mapping of the organizational process are common activities in both projects. Furthermore, the costs and the completion time for the projects will decrease (Thompson, 1967). Projects' interdependencies are not negligible in many situations. If we can model a significant part of projects' interdependencies in a portfolio, it results in selecting a set of harmonic projects and increasing the success probability of the portfolio (Kundisch \& Christian, 2011). Furthermore, practical findings of researchers emphasize that modeling projects' interdependencies can lead to advantages such as profitability and effective management of the resources pool (Kundisch \& Christian, 2011).

In this study, we developed a model to select a project portfolio considering several types of interdependencies between paired projects and resource constraints to align the portfolio with the strategic objectives of an organization. The required procedures

* Corresponding author.

E-mail address: ashrafi.mm@aut.ac.ir (M. Ashrafi) 
to model and quantify the effect of paired projects' interdependencies were defined and applied to prioritize projects. The structure of this paper is as follows: Section 2 focuses on reviewing the literature on projects' interdependency concepts. Section 3 proposes the model and the process of project portfolio selection considering interdependencies between projects. In section 4, the results of applying the developed model are expressed for two numerical examples. Section 5 discusses the model validation. Finally, section 6 addresses the conclusion and main findings of this research.

\section{Literature review}

Literature review of projects' interdependencies can be divided into two distinct parts: (1) theoretical foundations, including main concepts related to project interdependencies, and (2) findings related to considering projects' interdependencies in portfolio selection problems. When a project affected by other projects of a portfolio in any way, project interdependency occurs at different levels of a project such as tasks, objectives, and project level as a whole. Bathallath et al. (2016) investigated different types of projects' interdependencies, particularly in IT/IS project portfolios. They mentioned the most common types of projects' interdependencies as follows: resource interdependencies, technology interdependencies, technical interdependencies, market interdependencies, and learning-based interdependencies (Bathallath, Smedberg, \& Kjellin, 2016). Resource interdependencies take place when a project needs to use (a) resource(s) of (an)other project(s) in a portfolio. For example, consider "an expert participating in different projects simultaneously. Otherwise, each project is required to wait until that expert is released" (Bathallath, Smedberg, \& Kjellin, 2016). When a set of projects in a project portfolio uses specific technical knowledge to achieve each project's goals, technology interdependencies occur. For instance, "a project of developing a new generation of CPUs is likely to be dependent on another project developing a new operating system" (Bathallath, Smedberg, $\&$ Kjellin, 2016). The projects complement each other by sharing the design knowledge to produce a reliable computer (Bathallath, Smedberg, \& Kjellin, 2016).

Technical interdependencies mean the dependency of success or failure of a project to success or failure of another project on different levels from activities to the whole project. As an example, consider this situation: the implementation of a data warehouse system as a project and implementation of a business intelligence tool as another project which relies on data being accurately extracted and stored by the data warehouse system (Bathallath, Smedberg, \& Kjellin, 2016). Market interdependencies are concerned about the results of a project that may affect the results of another project in a project portfolio because that project's success is dependent on market conditions. For instance, "the installation of a project capable of providing advanced digital communication solutions is inevitably going to break up a project capable of providing analog communication" (Bathallath, Smedberg, \& Kjellin, 2016). In such circumstances, portfolio managers should readjust the configuration of a project portfolio to enhance the compatibility between projects and market conditions. Learning-based interdependencies refer to the use of the results of each project to complete (an)other project(s). These results may include knowledge, capabilities gained through each project. For example, "It can be more beneficial for a service development team to utilize the available knowledge (documentation and expertise) of a previous project to develop a new service with more attractive features" (Bathallath, Smedberg, \& Kjellin, 2016).

Bathallath et al. (2016) also discussed the interaction patterns of interdependent projects by analyzing two approaches mentioned by Thompson (1967) and Kundisch and Christian (2011). Thompson (1967) concluded that there are three different types of interaction patterns, including pooled, sequential, and reciprocal patterns. Pooled dependency is a seamless link between projects in which the output of a project can have an indirect effect on all or some of the projects (Thompson, 1967). In other words, a project could be independent of other projects, but the failure in achieving the result of a project can be a threat to the rest of the projects within the portfolio. Sequential dependence refers to serial relationships between two or more projects in which a project needs the output(s) of (an)other project(s) to be completed (Thompson, 1967). Reciprocal interdependence is related to mutual relations between two or more projects (Thompson, 1967). It means that the output of the project "A" could be considered as the input for project "B" and mutually the output of project "B" could be used as the input of project " $A$ ". Another aspect of projects' interdependencies is the classification proposed by Kundisch and Christian (2011). They combined a set of rules, which help to understand the effects of interdependencies between IT/IS projects in a portfolio. They identified three different forms for projects' interdependencies: (1) Resource-Resource, (2) Output-Output, and (3) Output-Resource (Kundisch \& Christian, 2011).

Resource-Resource interactions are concerned about sharing resources between projects to optimize organizational performance and gain economic advantage. For example, an expert could involve two or more projects at the same time. The decrease in completion costs of the portfolio is considered as one of the results for these interactions (Kundisch \& Christian, 2011). Output-Output interactions are the relationships between the result(s)/product(s) of two or more projects such that the total produced outputs by projects can cause different performance in the portfolio (Kundisch \& Christian, 2011). OutputResource interactions are related to the possible relationships between the output of one or more projects and the required resources of other projects (Kundisch \& Christian, 2011). Killen et al. (2009) used dependency matrices representing the relationships between any paired projects of a portfolio (such as $\mathrm{Pi}$ and $\mathrm{Pj}$ ) on both $\mathrm{x}$ and $\mathrm{y}$-axis like "From-To" chart. The main limitation of applying dependency matrices is that they are not able to conclude the transitive relation between any paired. Hence, Killen and Kjaer (2012) recommended that the network diagram can show the interdependencies between projects visually. Bai et al. (2018) applied composite system theory and synergy for modeling the project portfolio selection 
in which project portfolio selection known as a composite system constituted of three subsystems as follows: environment, project portfolio, and organizational strategic objectives. In one of the most recent studies, researchers investigated the resource constraints and need for sharing the resources between the projects of an organization. They utilized the exponential function to estimate the synergy, which refers to resource transferring between projects in a specific time horizon (Hemmatizadeh \& Mohammadi, 2019).

Almeida and Duarte (2011) studied synergies of projects based on benefits attained by interactions between projects using nonlinear integer programming. They calculated project synergies by scores that decision-makers allocate to the priorities of each criterion. Furthermore, Lopez and Almeida (2015) proposed a model for prioritization of projects by evaluating projects' synergies in a portfolio. This study aimed to provide a model based on Multi-Attribute Utility Theory (MAUT) to help to prioritize development projects in the oil and gas industry (Lopes \& Almeida, 2015). MAUT considers the structure of a decision maker's preferences in a multi-attribute decision-making process. According to possible synergies of oil and gas projects, the project portfolio was evaluated by the summation of multi-attribute utilities. Three attributes were considered for the project portfolio selection (Lopes \& Almeida, 2015): (1) maximization of return on investment by calculating the NPV, (2) increasing hydrocarbon production; and (3) minimization of political risk. In some cases, project interdependencies could influence the complexity of projects and cause to change project completion time or even may affect the success or failure of the whole project portfolio. Iranmanesh et al. (2019) developed a model in which project portfolio selection was performed by consideration of the synergistic impact of projects' interdependencies. Analyzing recent studies on projects interdependencies, we concluded that the research gap in this field could be interpreted as follows: (1) most studies defined and modeled projects synergies do not consider the factors causing synergy; (2) lack of a mathematical model to consider factors causing synergies in a portfolio is a significant limitation, and (3) there is a critical weakness in analyzing the different types of projects interdependencies. So, the authors attempted to concentrate on the aforementioned gap as much as possible.

\section{Measuring the potential synergies of projects}

Depending on the nature of the factors causing dependency and the type of interaction pattern addressed in the previous section, specific methods are proposed to measure the potential synergy between each couple of projects. Each factor affects one or more portfolio selection criteria. In summary, the factors, interaction patterns, and criteria influenced by each factor are addressed in Table 1.

\section{Table 1}

Factors causing dependency and reciprocal interaction patterns

\begin{tabular}{lll}
\hline Factors causing dependency & Interaction pattern & Reciprocal criterion \\
\hline Shared resource & Resource-Resource & Cost reduction \\
Technology and knowledge & Resource-Resource & Time reduction \\
Technical factors & Output-Resource & Succeeding in strategic objectives \\
Market & Output-Output & Increasing expected return \\
\hline
\end{tabular}

It should be noted that in the proposed framework, there is no limitation to select the most related criterion for project portfolio selection model. Given the factors causing dependency and the pattern of their interactions, various procedures are proposed to calculate the potential synergy.

\subsection{Interactions between projects from the resource's perspective}

Suppose that project $A$ and project $B$ are interdependent in terms of resources with estimated costs $C_{A}$ and $C_{B}$, respectively, such that $C_{B}>C_{A}$. These two projects synergy in reducing the total cost of their resources is calculated as follows:

- The binary relationship of each couple of projects in terms of resources is displayed with two directed arcs between two nodes representing the projects (Fig. 1);

- The share of each project to use resources allocated to the portfolio is determined using a square matrix. The ratio is shown with $r_{i j}$. For example, suppose that projects $A$ and $B$ ( $i$ and $j$ indices, respectively) have resource interdependency. Project $A$ uses up to $30 \%$ of the resources, and the remaining $70 \%$ of resources are allocated to project $B$, the relationship between $r_{i j}$ and $r_{j i}$ is as follows:

$$
r_{i j}=1-r_{j i}
$$

- The simultaneous selection of these two projects results in a decrease in the total cost of the resources, which is called $D C_{i j}$ and written on each arc. 
- Finally, the amount of each project contribution to the project portfolio total cost reduction as a result of resource interdependency $\left(R D_{i}\right)$ is calculated using the following equation:

$$
R D_{i}=\sum_{j \neq i} r_{i j} \times D C_{i j}
$$

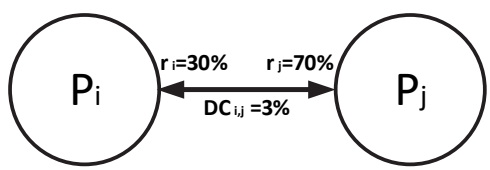

Fig. 1. Graphical view of projects interactions caused by the shared resources

\section{Technical knowledge and learning interactions between projects}

The use of existing knowledge and technologies posed in a market can increase the speed of technology transfer and learning. This may lead to a reduction in the completion time of some projects and consequently that of the project portfolio. The following steps are proposed to calculate the score for each project potential to create learning synergy in a project portfolio:

- The binary relationship of each couple of projects in terms of learning and common technologies are displayed with two directed arcs between nodes;

- The contribution of each project to use common technical knowledge in a portfolio is determined using a square matrix. If projects $A$ and $B$ ( $i$ and $j$ indices, respectively) have technology interdependency, $r_{i j}^{\prime}$ shows the percentage of technical knowledge interdependency of project $A$ with project $B$;

- The percentage decrease in portfolio completion time by the simultaneous selection of these two projects is written on each arc, $D T_{i j}$ (Fig. 2);

- Finally, the amount of each project contribution to the reduction of a project portfolio completion time by learning and technology interdependency $\left(L T_{i}\right)$ is calculated using Eq. (3):

$$
L T_{i}=\sum_{j \neq i} r_{i j}^{\prime} \times D T_{i j}
$$

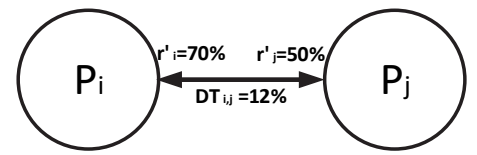

Fig. 2. Graphical view of projects interactions caused by technology transfer and learning

\section{Technical interactions between projects}

The effectiveness of each project can be estimated from its influence on the probability of other projects' success. The conditional success probability of a project given the joint distribution of other projects is obtained from Eq. (4):

$$
P_{A \mid B_{1}, B_{2}, \ldots, B_{n}}=\frac{P_{\left(A \cap B_{1} \cap B_{2} \cap \ldots \cap B_{n}\right)}}{P_{\left(B_{1}, B_{2}, \ldots, B_{n}\right)}}
$$

The information on the joint distribution for each couple of projects can be acquired from experts' judgments on all candidate projects for a project portfolio. Fig. 3 shows the technical dependency between project $A$ and project $C$ with a causal effect on project $B$.

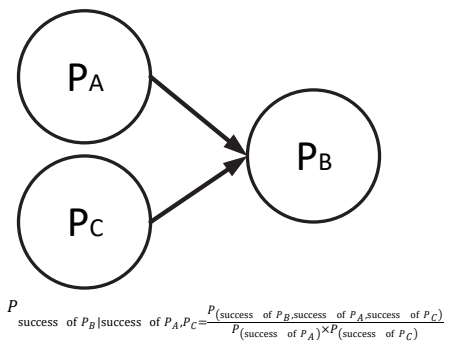

Fig. 3. Technical dependence (3-Variables joint probability distribution) 


\section{Target market interactions between projects}

Each project outcome may affect other projects in terms of expected incomes or sales amounts. This type of interaction for the target market factor is considered as an outcome-outcome interaction, which is estimated as follows:

- The percentage of increase in total sales of each couple of projects products are written on two directed arcs in a project portfolio network (Fig. 4);

- $\quad$ The square matrix resulting from these interdependencies is created from the developed network;

- The amount of each project revenue can be calculated directly as the project net present value or indirectly obtained using the Likert spectrum using experts' survey;

- The synergy amount of each couple of projects is called Market interdependency $\left(M I_{i}\right)$ and can be obtained from Eq. (5):

$$
\forall(i, j) \epsilon S \quad M I_{i}=\sum_{j} \text { Outcome }_{j} \times \text { Synergy }_{i, j}
$$

In the above equation, the ordered pair $(i, j)$ is a member of the project set $S$ to show that the outcome of each project affects the performance of the whole portfolio in a market. The variable Outcome $e_{j}$ represents the amount of the project $j$ revenue and the variable $S y n e r g y_{i, j}$ represents the synergy percentage of the project's revenue when both $i$ and $j$ projects located in a portfolio.

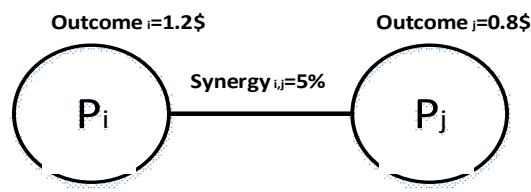

Fig. 4. Graphical view of projects interactions caused by market interdependency

\section{Model development}

This paper aims to represent a mathematical model, in which the projects' interdependencies are involved in the portfolio selection process as well as factors causing the interactions between projects. Fig. 5 shows the proposed problem-solving framework for selecting a project portfolio.

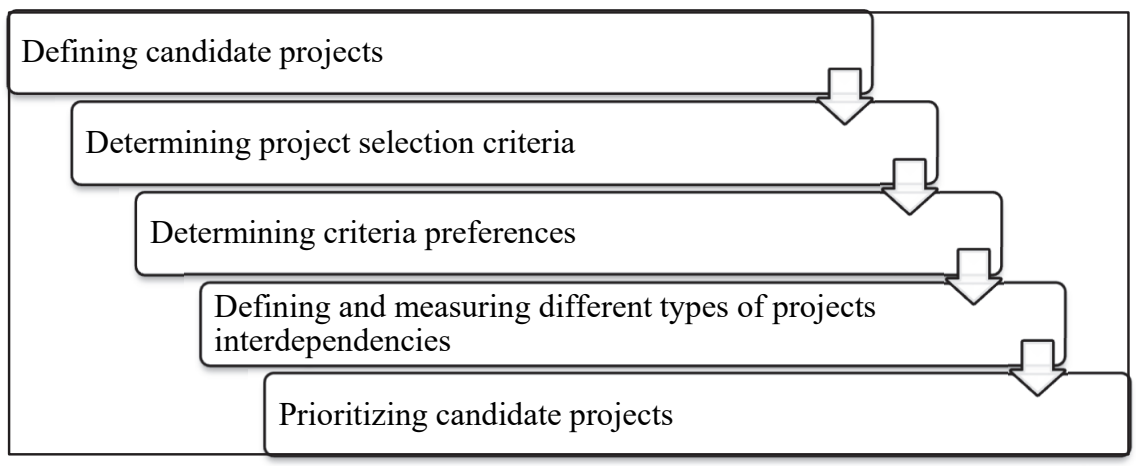

Fig. 5. The proposed framework for project portfolio selection

Various models of project portfolio selection have been focused on modeling the synergy between projects, but they considered different assumptions and constraints. In this research, the following assumptions are supposed:

(1) The relationships between projects are considered as a couple. In other words, interdependencies between more than two projects are not considered due to the high complexity;

(2) It is assumed that the cost and expected revenue of each project were calculated in the feasibility study phase of that project. Because of the uncertain nature of the cost and expected revenue, their probability distribution function can be used;

(3) Each project criteria value, such as time, cost, and revenues are supposed to change linearly in terms of creating the synergy resulting from the selection of a couple of interdependent projects. 


\subsection{Projects prioritization}

The Promethee method is widely used as a technique to rank alternatives because of its transparent use of computational approaches and simplicity to be understood by decision-makers (Behzadian, Kazemzadeh, Albadvi, \& Aghdasi, 2010; Georgopoulou, Sarafidis, \& Diakoulaki, 1998). It is based on a preference function addressing the difference in the value of two alternatives in terms of the $j^{\text {th }}$ criterion, namely, $d_{j}$ (Shakhsi-Niaei, Torabi, \& Iranmanesh, 2011). In Eq. (6), $f(a, j)$ and $f(b, j)$ are the performance values of the alternatives $a$ and $b$ in terms of criterion $j$.

$$
d_{j}=f(a, j)-f(b, j)
$$

There are six different function types proposed for different criteria to calculate the $d_{j}$ value (Brans, Vincke, \& Mareschal, 1986). We chose among these preference functions according to the interdependency type, which is expressed in the following section. The criteria for selecting the project portfolio were coordinated with the defined types of interdependencies and are as follows: minimizing the portfolio total cost, and completion time and maximizing its success probability and revenue, which were transformed to an augmented score for each project applying Promethee II method. After implementing the Promethee II method steps, each project takes its score, and projects are prioritized according to their net flows. We applied Mavrotas et al. (2008) algorithm to select the project portfolio, which guarantees the consistency of the final selected project portfolio with the rank of each project at the prioritization step by introducing an augmented score. The fundamental difference between the final selected projects and projects ranks results from considering budget limitation. Considering the budget constraint, the model tends to select projects with lower cost, which results in a gap between the final selected projects and projects' ranks (Mavrotas, Diakoulaki, \& Kourentzis, 2008). Augmented scores in the Mavrotas et al. (2008) algorithm solve this problem. The augmented score of the project $i\left(a s_{i}\right)$ has the feature that no combinations of projects ranked below the $P_{i}$ with cost less than $P_{i}$ can have augmented scores more than that of $P_{i}$. The projects were arranged in ascending order according to their multi-criteria scores to calculate the augmented scores. So that the first project was the project that has the worst score in the prioritization process. For the worst project, the augmented score equals to 1 and then, the Knapsack problem was solved for the $k^{\text {th }}$ project $(k=1, \ldots, n)$ to find the value of $Z_{k}$ (Mavrotas, Diakoulaki, \& Kourentzis, 2008):

$$
\begin{aligned}
& \min _{\text {subject to }} Z_{k}=\sum_{i=1}^{k-1} a s_{i} x_{i} \\
& \sum_{i=1}^{k-1} C_{i} x_{i} \leq C_{k}, \quad x_{i} \in\{0,1\}
\end{aligned}
$$

where $C_{i}$ is the cost of project $i$, and $k$ index is equal to the number of the projects for which the augmented score has to be calculated. Since the candidate projects in this research were interdependent, and the factors causing dependency to affect the cost or revenue performance of the project portfolio, the equation (8) should be modified as follows (equation 9) to consider projects interdependencies in a portfolio:

$$
\sum_{i=1}^{k-1} C_{i} x_{i}-\sum_{i, j \in A}\left(D C_{i j} \times\left(C_{i}+C_{j}\right)\right) \leq C_{k}, \quad x_{i} \in\{0,1\} \quad \text { A: Set of interdependent projects }
$$

The logic of this modified constraint is that a project examined to calculate its augmented score can be replaced by all projects worse than it in the portfolio. For all projects that create synergy in terms of cost, their collective cost reduction should be considered in this constraint. Therefore, the cost reduction percentage of projects $i$ and $j\left(D C_{i j}\right)$ was multiplied by the total cost of the two projects $\left(C_{i}+C j\right)$. This operation was repeated for all combinations of each couple of projects. Finally, a more precise evaluation process for the replacement of the $k^{\text {th }}$ project was obtained at the next steps of the Mavrotas et al. (2008) algorithm. After calculating $Z_{k}$, if $Z_{k}>a s_{k-1}$, then the augmented score of the $k^{\text {th }}$ project is equal to:

$$
a s_{k}=Z_{k}+1
$$

and if $Z_{k} \leq a s_{k-1}$, then the augmented score of the $k^{\text {th }}$ project is equal to:

$$
a s_{k}=a s_{k-1}+1
$$

\subsection{Project portfolio selection}

After calculating the projects' augmented scores, the process of portfolio project selection was started. If the projects' interdependencies are not considered in the model, this problem can be solved by linear integer programming. In this study, considering the synergy of projects in a portfolio, the problem became more complicated, and nonlinear integer programming 
was used. Eq. (12) shows the objective function of the model:

$$
\max \quad Z=\sum_{i=1}^{n} a s_{i} x_{i}
$$

where $x_{i}$ is a binary variable, which equals to 1 if project $i$ selected for the project portfolio and $a s_{i}$ is the augmented score of project $i$. The most important constraint of this model is the budget limitation, which is written below:

$$
\sum_{i=1}^{k-1} C_{i} x_{i}-\sum_{i, j \in A}\left(D C_{i j} \times\left(C_{i}+C_{j}\right)\right) \times Y_{i j} \leq \text { Budget }, \quad x_{i}, Y_{i j} \in\{0,1\}
$$

Eq. (13) is a general budget limitation for a portfolio selection problem in which projects' interdependencies are also included. $Y_{i j}$ is synergy in the reducing of the total cost of projects $i$ and $j$ and its value is equal to the multiplication of the variables $x_{i}$ and $x_{j}$ (Eq. (14)).

$$
Y_{i j}=x_{i} \times x_{j}, \quad x_{i}, x_{j} \in\{0,1\}
$$

\section{A Numerical Example}

As a numerical example to demonstrate the model application, nine candidate projects are defined for a project-oriented company $\left(P_{1}, \ldots, P_{9}\right)$. To choose from the candidate projects and form a portfolio, the synergy effects of these projects should be considered. In the proposed model, the criteria for selecting the project portfolio were minimizing the portfolio total cost, and completion time and maximizing its success probability and revenue, which were transformed to an augmented score for each project applying the Promethee II method. The identified interdependencies between project couples affect the values of the aforementioned criteria as follows:

- $\quad$ resource interdependencies lead to wages and salaries reduction

- learning and technical knowledge interdependencies cause to reduce the completion time of projects in a portfolio

- technical interdependencies improve the success probabilities of projects

- $\quad$ projects' interdependencies in the target market increase the sales or expected revenue of a project outcome.

Table 2 shows the criteria used for the prioritization of projects, the consistent preference function type, and the required parameters for the implementation of the Promethee II method.

Table 2

Criteria and type of preference functions in the Promethee II method for a numerical example

\begin{tabular}{lllc}
\hline Criterion & Description & Function Type & P \\
\hline \multirow{3}{*}{ Cost reduction } & $\begin{array}{l}\text { Quantitative approach with a low variance; } \\
\text { Preference threshold is the essential and indifferent } \\
\text { area is not important }\end{array}$ & linear preference & 4 \\
Time reduction & $\begin{array}{l}\text { Quantitative criterion with a little variance; } \\
\text { Preference threshold is the vital and detached area is } \\
\text { not important }\end{array}$ & linear preference & 10 \\
Success probability & $\begin{array}{l}\text { Qualitative criterion, } \\
\text { Unit: percent; } \\
\text { improvement }\end{array}$ & $\begin{array}{l}\text { Preference threshold is important } \\
\text { Quantitative approach with wide variation range and } \\
\text { variance, }\end{array}$ & Level Criterion \\
Sales improvement & $\begin{array}{l}\text { Unit: currency; } \\
\text { Preference threshold and the indifferent area is } \\
\text { important }\end{array}$ & $\begin{array}{l}\text { linear preference and } \\
\text { indifference area }\end{array}$ & 3.5 \\
\hline
\end{tabular}

The interdependency networks of the nine candidate projects are shown in Figs. 6-9. 


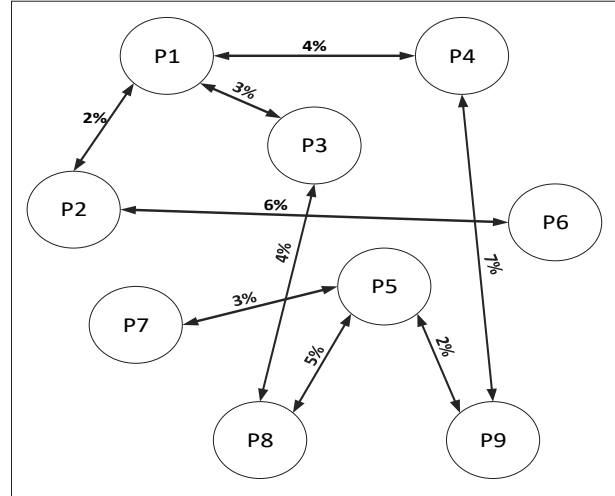

Fig. 6. Resource interdependencies network



Fig. 8. Technical interdependencies network

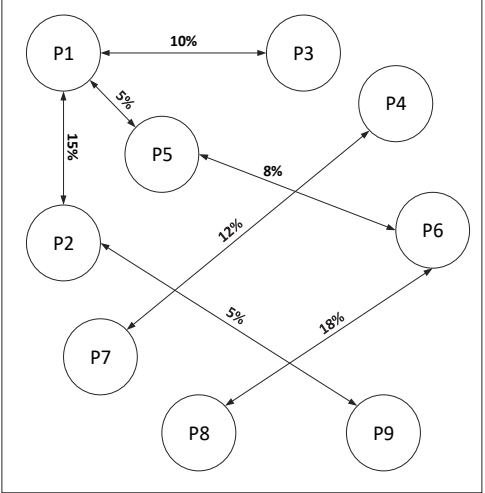

Fig. 7. Technology and knowledge interdependency network

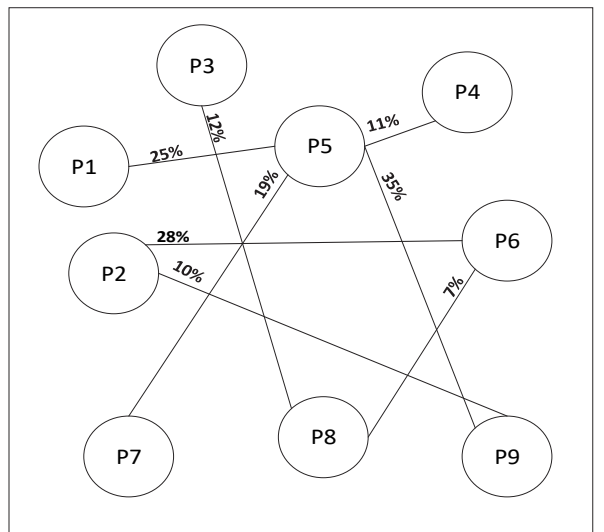

Fig. 9. Market interdependencies network

The value matrix of $r_{i j}$ and $r_{i j}^{\prime}$ are shown in Table 3 and Table 4, respectively.

Table 3

$r_{i j}$ values matrix of projects

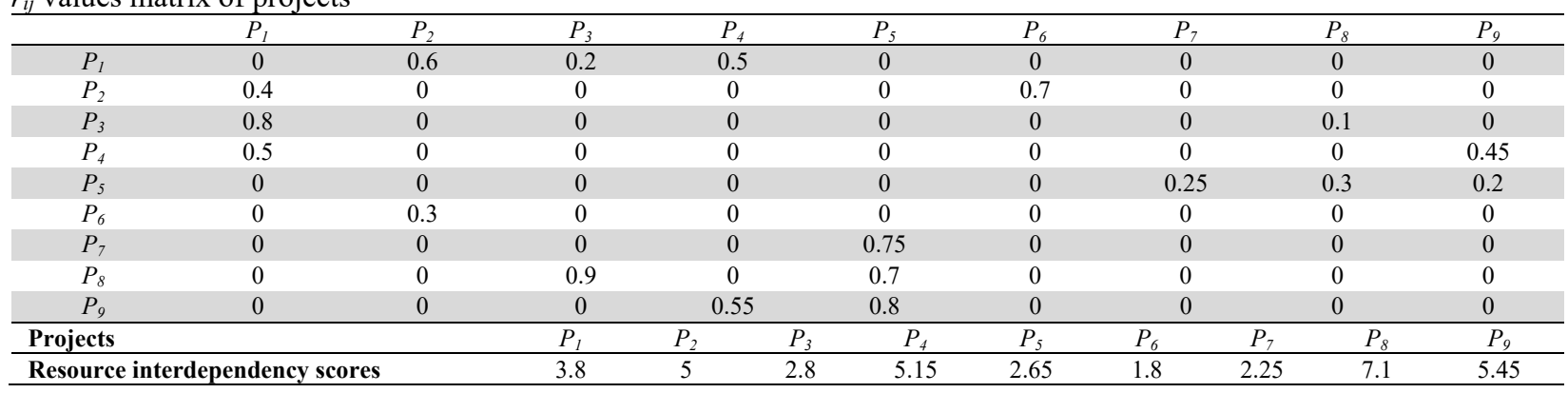

Table 4

$r_{i j}^{\prime}$ values matrix of projects

\begin{tabular}{|c|c|c|c|c|c|c|c|c|c|c|}
\hline & $P_{1}$ & $P_{2}$ & $P_{3}$ & $P_{4}$ & & $P_{5}$ & $P_{6}$ & $P_{7}$ & $P_{8}$ & $P_{9}$ \\
\hline$P_{l}$ & 0 & 0.25 & 0.1 & 0 & & 0.35 & 0 & 0 & 0 & 0 \\
\hline$P_{2}$ & 0.75 & 0 & 0 & 0 & & 0 & 0 & 0 & 0 & 0.7 \\
\hline$P_{3}$ & 0.9 & 0 & 0 & 0 & & 0 & 0 & 0 & 0 & 0 \\
\hline$P_{4}$ & 0 & 0 & 0 & 0 & & 0 & 0 & 0.5 & 0 & 0 \\
\hline$P_{5}$ & 0.65 & 0 & 0 & 0 & & 0 & 0.4 & 0 & 0 & 0 \\
\hline$P_{6}$ & 0 & 0 & 0 & 0 & & 0.6 & 0 & 0 & 0.63 & 0 \\
\hline$P_{7}$ & 0 & 0 & 0 & 0.5 & & 0 & 0 & 0 & 0 & 0 \\
\hline$P_{8}$ & 0 & 0 & 0 & 0 & & 0 & 0.37 & 0 & 0 & 0 \\
\hline$P_{9}$ & 0 & 0.3 & 0 & 0 & & 0 & 0 & 0 & 0 & 0 \\
\hline Projects & & & & $P_{1}$ & $P_{2}$ & $P_{3}$ & $P_{4}$ & $P_{6}$ & $P_{7}$ & $P_{9}$ \\
\hline Technolo & depen & res & & 6.5 & 14.75 & 9 & 6.45 & 16.14 & 6.66 & 1.5 \\
\hline
\end{tabular}

Gathering the primary data for the success and failure probabilities of projects couples having technical interdependencies, the calculation of the projects' joint probability distribution functions is shown in Table 5. 
Table 5

Calculation of projects success joint probability distribution functions caused by technical interdependencies

\begin{tabular}{|c|c|c|c|c|c|c|c|c|c|}
\hline \multirow{2}{*}{$\begin{array}{l}\text { Projects } \\
\text { (P4, P5) }\end{array}$} & \multicolumn{3}{|c|}{ Primary data } & \multicolumn{3}{|c|}{ Making positive the probabilities } & \multicolumn{3}{|c|}{ Probability normalizing } \\
\hline & success of $\mathrm{P} 4$ & failure of P4 & & success of P4 & $\begin{array}{c}\text { failure of } \\
\text { P4 }\end{array}$ & & $\begin{array}{c}\text { success of } \\
\text { P4 }\end{array}$ & $\begin{array}{l}\text { failure } \\
\text { of P4 }\end{array}$ & \\
\hline & 0.2 & 0.4 & failure of P5 & 0.2 & 0.4 & failure of P5 & 0.2 & 0.4 & failure of P5 \\
\hline & 0.1 & 0.3 & success of P5 & 0.1 & 0.3 & success of P5 & 0.1 & 0.3 & success of P5 \\
\hline \multirow[t]{3}{*}{ (P5, P7) } & success of P5 & failure of P5 & & success of P5 & $\begin{array}{c}\text { failure of } \\
\text { P5 }\end{array}$ & & $\begin{array}{c}\text { success of } \\
\text { P5 } \\
\end{array}$ & $\begin{array}{c}\text { failure } \\
\text { of P5 }\end{array}$ & \\
\hline & 0.1 & 0.65 & failure of P7 & 1.54 & 2.09 & failure of P7 & 0.23 & 0.31 & failure of P7 \\
\hline & -0.44 & 0.69 & success of P7 & 1 & 2.13 & success of $\mathrm{P} 7$ & 0.15 & 0.32 & success of $\mathrm{P} 7$ \\
\hline \multirow[t]{3}{*}{$(\mathrm{P} 7, \mathrm{P} 6)$} & success of $\mathrm{P} 7$ & failure of P7 & & success of P7 & $\begin{array}{c}\text { failure of } \\
\text { P7 }\end{array}$ & & $\begin{array}{c}\text { success of } \\
\text { P7 }\end{array}$ & $\begin{array}{c}\text { failure } \\
\text { of P7 }\end{array}$ & \\
\hline & 0.56993 & 0.236072 & failure of P6 & 0.57 & 0.24 & failure of P6 & 0.57 & 0.24 & failure of P6 \\
\hline & 0.179413 & 0.014585 & success of P6 & 0.18 & 0.01 & success of P6 & 0.18 & 0.01 & success of P6 \\
\hline \multirow[t]{3}{*}{$(\mathrm{P} 8, \mathrm{P} 2)$} & success of P8 & failure of P8 & & success of $\mathrm{P} 8$ & failure of & & success of & failure & \\
\hline & 0.69284 & 0.27383 & failure of P2 & 2.17 & 1.75 & failure of P2 & 0.31 & 0.25 & failure of $\mathrm{P} 2$ \\
\hline & -0.4732 & 0.50652 & success of P2 & 1 & 1.98 & success of P2 & 0.15 & 0.29 & success of $\mathrm{P} 2$ \\
\hline \multirow[t]{3}{*}{ (P9, P3) } & success of P9 & failure of P9 & & success of P9 & $\begin{array}{c}\text { failure of } \\
\text { P9 }\end{array}$ & & $\begin{array}{c}\text { success of } \\
\text { P9 }\end{array}$ & $\begin{array}{l}\text { failure } \\
\text { of } P 9\end{array}$ & \\
\hline & 0.50121 & 0.17291 & failure of P3 & 0.5 & 0.17 & failure of P3 & 0.5 & 0.17 & failure of P3 \\
\hline & 0.0682 & 0.25767 & success of P3 & 0.07 & 0.26 & success of P3 & 0.07 & 0.26 & success of P3 \\
\hline \multirow[t]{3}{*}{$(\mathrm{P} 6, \mathrm{P} 1)$} & success of P6 & failure of P6 & success of $\mathrm{P} 2$ & success of P6 & $\begin{array}{c}\text { failure of } \\
\text { P6 }\end{array}$ & & $\begin{array}{c}\text { success of } \\
\text { P6 }\end{array}$ & $\begin{array}{c}\text { failure } \\
\text { of P6 }\end{array}$ & \\
\hline & 0.24656 & 0.8232 & failure of P1 & 3.62 & 4.19 & failure of $\mathrm{P} 1$ & 0.13 & 0.15 & failure of P1 \\
\hline & 0.56013 & 0.25891 & success of $\mathrm{P} 1$ & 3.93 & 3.63 & success of $\mathrm{P} 1$ & 0.14 & 0.13 & success of $\mathrm{P} 1$ \\
\hline \multirow[t]{3}{*}{$(\mathrm{P} 6, \mathrm{P} 1)$} & success of P6 & failure of P6 & failure of P2 & success of P6 & $\begin{array}{c}\text { failure of } \\
\text { P6 }\end{array}$ & & $\begin{array}{c}\text { success of } \\
\text { P6 }\end{array}$ & $\begin{array}{c}\text { failure } \\
\text { of } \mathrm{P6}\end{array}$ & \\
\hline & 0.47662 & 0.52633 & failure of $\mathrm{P} 1$ & 3.85 & 3.9 & failure of P1 & 0.14 & 0.14 & failure of $\mathrm{P} 1$ \\
\hline & -2.3691 & 0.47738 & success of P1 & 1 & 3.85 & success of P1 & 0.04 & 0.14 & success of P1 \\
\hline
\end{tabular}

Then, we calculated the technical interdependence score of each project, as shown in Table 6.

Table 6

Technical interdependency scores of projects

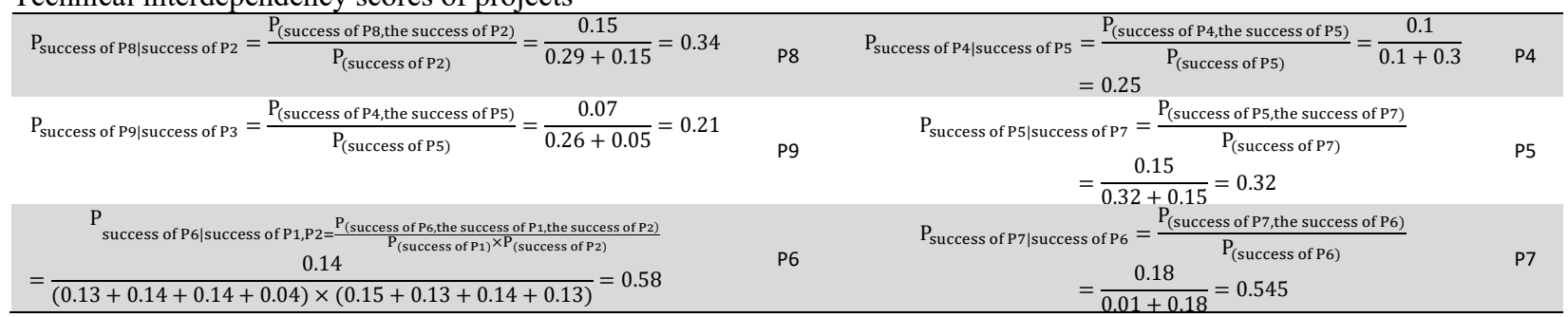

The performance data of projects in the target market and the calculated market interdependence scores of projects are shown in Table 7 and Table 8, respectively.

Table 7

Value matrix of synergy $y_{i j}$ and outcome

\begin{tabular}{ccccccccccc}
\hline & $P_{1}$ & $P_{2}$ & $P_{3}$ & $P_{4}$ & $P_{5}$ & $P_{6}$ & $P_{7}$ & $P_{8}$ & $P_{9}$ & Existing sale \\
\hline$P_{l}$ & 0 & 0 & 0 & 0 & 0.25 & 0 & 0 & 0 & 0 & 10 \\
$P_{2}$ & 0 & 0 & 0 & 0 & 0 & 0.28 & 0 & 0 & 0.1 & 15 \\
$P_{3}$ & 0 & 0 & 0 & 0 & 0 & 0 & 0 & 0.12 & 0 & 12.5 \\
$P_{4}$ & 0 & 0 & 0 & 0 & 0.11 & 0 & 0 & 0 & 0 & 13 \\
$P_{5}$ & 0.25 & 0 & 0 & 0.11 & 0 & 0 & 0.19 & 0 & 0.35 & 8 \\
$P_{6}$ & 0 & 0.28 & 0 & 0 & 0 & 0 & 0 & 0.07 & 0 & 11 \\
$P_{7}$ & 0 & 0 & 0 & 0 & 0.19 & 0 & 0 & 0 & 0 & 5 \\
$P_{8}$ & 0 & 0 & 0.12 & 0 & 0 & 0.07 & 0 & 0 & 0 & 0 \\
$P_{9}$ & 0 & 0.1 & 0 & 0 & 0.35 & 0 & 0 & 0 & 0 & 21 \\
\hline
\end{tabular}

Table 8

Sales improvement of projects

\begin{tabular}{cccccccccc}
\hline Projects & $P_{1}$ & $P_{2}$ & $P_{3}$ & $P_{4}$ & $P_{5}$ & $P_{6}$ & $P_{7}$ & $P_{8}$ & $P_{9}$ \\
\hline Sales improvement scores & 2 & 5.18 & 1.08 & 0.88 & 12.23 & 4.83 & 1.52 & 2.27 & 4.3 \\
\hline
\end{tabular}


In this example, the criteria weights were assigned according to Table 9.

Table 9

Criteria weights

\begin{tabular}{lcccc} 
Criteria & Cost reduction & Time reduction & Success probability improvement & Sales improvement \\
\hline Weights & 0.2 & 0.3 & 0.15 & 0.35 \\
\hline
\end{tabular}

Finally, Table 10 shows the projects' ranking based on the Promethee II implementation.

Table 10

Project ranking using the Promethee II

\begin{tabular}{|c|c|c|c|c|c|c|c|c|c|}
\hline & $P_{I}$ & $P_{2}$ & $P_{3}$ & $P_{4}$ & $P_{5}$ & $P_{6}$ & $P_{7}$ & $P_{8}$ & $P_{9}$ \\
\hline$\varphi^{+}$ & 0.073 & 0.501 & 0.089 & 0.124 & 0.417 & 0.549 & 0.162 & 0.246 & 0.284 \\
\hline$\varphi^{-}$ & 0.342 & 0.141 & 0.387 & 0.328 & 0.187 & 0.169 & 0.349 & 0.234 & 0.31 \\
\hline$\varphi$ & -0.269 & 0.36 & -0.298 & -0.204 & 0.23 & 0.38 & -0.187 & 0.012 & -0.026 \\
\hline Rank & 8 & 2 & 9 & 7 & 3 & 1 & 6 & 4 & 5 \\
\hline
\end{tabular}

After obtaining the projects' multi-criteria scores $(\mathrm{ms})$ and the initial ranking of the projects applying the PrometheeII method, we applied the Mavrotas et al. (2008) algorithm to get the augmented score of each project. It was performed in a VBA environment, using Excel software solver. The Knapsack problem was solved for each repetition of the algorithm. The results for the augmented scores of projects are shown in Table 11.

Table 11

Augmented scores of projects

\begin{tabular}{|c|c|c|c|c|c|}
\hline Projects & $m s$ & Cost & $K$ & as $(i)$ & $Z(k)$ \\
\hline$P_{3}$ & -0.298 & 1649 & 1 & 1 & - \\
\hline$P_{1}$ & -0.269 & 497 & 2 & 2 & 0 \\
\hline$P_{4}$ & -0.204 & 1779 & 3 & 3 & 2 \\
\hline$P_{7}$ & -0.187 & 2192 & 4 & 6 & 5 \\
\hline$P_{9}$ & -0.026 & 907 & 5 & 7 & 2 \\
\hline$P_{8}$ & 0.012 & 4755 & 6 & 17 & 16 \\
\hline$P_{5}$ & 0.23 & 2151 & 7 & 18 & 10 \\
\hline$P_{2}$ & 0.36 & 638 & 8 & 19 & 9 \\
\hline$P_{6}$ & 0.38 & 202 & 9 & 22 & 21 \\
\hline
\end{tabular}

The budget limitation should be modeled by applying the synergy values of paired interdependent projects to form the final portfolio. In this problem, the total budget was assumed to be 10,000 monetary units. The final optimization model of project portfolio selection was a nonlinear integer model. Table 12 shows the model variables related to project cost synergies and coefficients of the objective function.

Table 12

Variables of the problem related to project cost synergies in a numerical example

\begin{tabular}{cccccc}
\hline Equivalent variable & Variable (0,1) & Interdependent Projects & Cost reduction & $\boldsymbol{P}_{\boldsymbol{i} . \boldsymbol{P}_{\boldsymbol{j}}}$ \\
\hline$Y_{12}$ & 0 & $P_{1}$ & $P_{2}$ & 22.7 & 0 \\
$Y_{13}$ & 0 & $P_{1}$ & $P_{3}$ & 64.38 & 0 \\
$Y_{14}$ & $P_{1}$ & $P_{4}$ & 91.04 & 0 \\
$Y_{26}$ & 0 & $P_{2}$ & $P_{6}$ & 50.4 & 0 \\
$Y_{38}$ & $P_{3}$ & $P_{8}$ & 256.16 & 0 \\
$Y_{49}$ & 0 & $P_{4}$ & $P_{9}$ & 188.02 & 0 \\
$Y_{57}$ & 0 & $P_{5}$ & 130.29 & 0 \\
$Y_{58}$ & 0 & $P_{5}$ & 345.3 & 0 \\
$Y_{59}$ & 0 & $P_{5}$ & $P_{8}$ & 61.16 & 0 \\
\hline
\end{tabular}

The model was solved after applying the budget limitation. The result of the final project portfolio selection is shown in Table 13.

Table 13

Optimal values of numerical example variables

\begin{tabular}{lcccccccc}
\hline Variable & $P_{1}$ & $P_{2}$ & $P_{3}$ & $P_{4}$ & $P_{5}$ & $P_{6}$ & $P_{7}$ & $P_{8}$ \\
\hline Optimal value & 1 & 1 & 1 & 0 & 1 & 1 & 0 \\
Variable & $Y_{12}$ & $Y_{13}$ & $Y_{14}$ & $Y_{26}$ & $Y_{38}$ & $Y_{49}$ & $Y_{57}$ & $Y_{58}$ \\
Optimal value & 1 & 1 & 0 & 1 & 1 & 0 & 0 \\
\hline
\end{tabular}


The total portfolio cost and its cost reduction are reported in Table 14.

Table 14

The result of the project portfolio cost

\begin{tabular}{lll}
\hline The total cost of projects & Sum-product $\left(C_{i \cdot} P_{i}\right)$ & 10,799 \\
\hline Overall cost reduction of projects & Sumproduct $\left(D C_{i \cdot} Y_{i j}\right)$ & 800.1 \\
\hline
\end{tabular}

\section{Discussion}

We implemented the model regardless of the synergy of projects again to validate the model. Its results were compared with the results of the model considering the synergy of the project. The most critical variable examined thorough the validation process was each project cost $\left(C_{i}\right)$. The parameters of the probability distribution function for this random variable are illustrated in Table 15. The model was run 50 times to simulate multiple repetitions, so 50 random numbers were generated for each project cost.

Table 15

The parameters of the projects cost normal distribution

\begin{tabular}{llllrrrrrr}
\hline Projects & $P_{1}$ & $P_{2}$ & $P_{3}$ & $P_{4}$ & $P_{5}$ & $P_{6}$ & $P_{7}$ & $P_{8}$ \\
\hline Mean & 1457 & 316 & 1645 & 1935 & 2351.5 & 1055.5 & 1836 & 2427.5 & 768.5 \\
Standard deviation & 31.85 & 73.91 & 1.6 & 7.82 & 19.08 & 6.5 & 26.75 & 9.48 & 22.21 \\
\hline
\end{tabular}

The remaining budget after project portfolio selection was an important indicator to examine portfolio balance. The greater the remaining budget, the higher the imbalance between projects in the portfolio. If the remaining budget is not significant, it means that the portfolio selection process is performed tightly according to the organization budget, and the maximum budget is used. Therefore, the remaining budget data in both cases (considering projects' synergy or not considering projects' synergy) were recorded and compared together. A T-student pairwise comparison test was carried on to compare the mean of these two data sets. Before performing a T-test to examine the normality of the data, the Kolmogorov-Smirnov test was done using SPSS 19-2010. Table 16 shows the result of performing the Kolmogorov-Smirnov test of data normality. RB1 is related to the remaining budget after project portfolio selection with consideration of synergic impacts and $R B 2$ is associated with the remaining budget of the portfolio after the project selection process without the consideration of synergic effects.

Table 16

Result of Kolmogorov-Smirnov test for remain budget data of 2 states

\begin{tabular}{cccc}
\hline $\boldsymbol{R} \boldsymbol{B} \boldsymbol{2}$ & $\boldsymbol{R B} \boldsymbol{2}$ & & $\mathrm{N}$ \\
1198.2325 & 50 & Normal Parameters & Mean \\
188.44306 & 162.4742 & & Std. Deviation \\
.256 & 113.84989 & Most Extreme Differences & Absolute \\
.181 & .124 & & Positive \\
-.256 & .124 & Negative \\
1.810 & -.112 & Kolmogorov-Smirnov Z \\
.003 & .879 & & Asymp. Sig. (2-tailed) \\
\hline
\end{tabular}

a. Test distribution is normal

b. Calculated from data

According to the Kolmogorov-Smirnov test analysis, we concluded that the remaining values of the budget in the case of assuming synergy between projects $(R B 1)$ follows the normal distribution. The test result for the data recorded from the second case showed that the associated distribution cannot be approximated by normal distribution at a significant level of 0.05 . Therefore, a nonparametric test, called the Wilcoxon test, was used to evaluate the similarity of the mean of the two dependent samples. This test was performed using the T-student pairwise comparison, in which the hypotheses $H_{0}$ and $H_{l}$ were addressed in Eq. (15). The result of the Wilcoxon test is shown in Table 17.

$$
\left\{\begin{array}{l}
H_{0}: \mu_{1}=\mu_{2} \\
H_{1}: \mu_{1} \neq \mu_{2}
\end{array} \quad \text { when } \sigma\right. \text { is unknown }
$$

Table 17

The result of the paired comparison of data on the Wilcoxon Test (Ranks)

\begin{tabular}{|c|c|c|c|c|}
\hline & & $\mathrm{N}$ & Mean Rank & Sum of Ranks \\
\hline \multirow[t]{4}{*}{$R B 2-R B 1$} & Negative Ranks & $49^{a}$ & 26.00 & 1274.00 \\
\hline & Positive Ranks & $1^{b}$ & 1.00 & 1.00 \\
\hline & Ties & $0^{\mathrm{c}}$ & & \\
\hline & Total & 50 & & \\
\hline
\end{tabular}

a. $R B 2<R B 1 \quad$ b. $R B 2>R B 1$ c. $R B 2=R B 1$ 
It can be concluded from Table 17 that the remaining budget amount in the case of assuming synergy between projects is less than that of the latter. Fig. 10 shows the remaining amounts of the portfolio budget in two cases. The horizontal axis of this chart shows simulation repetitions, and its vertical axis represents the residual values of the portfolio budget at each simulation repetition.

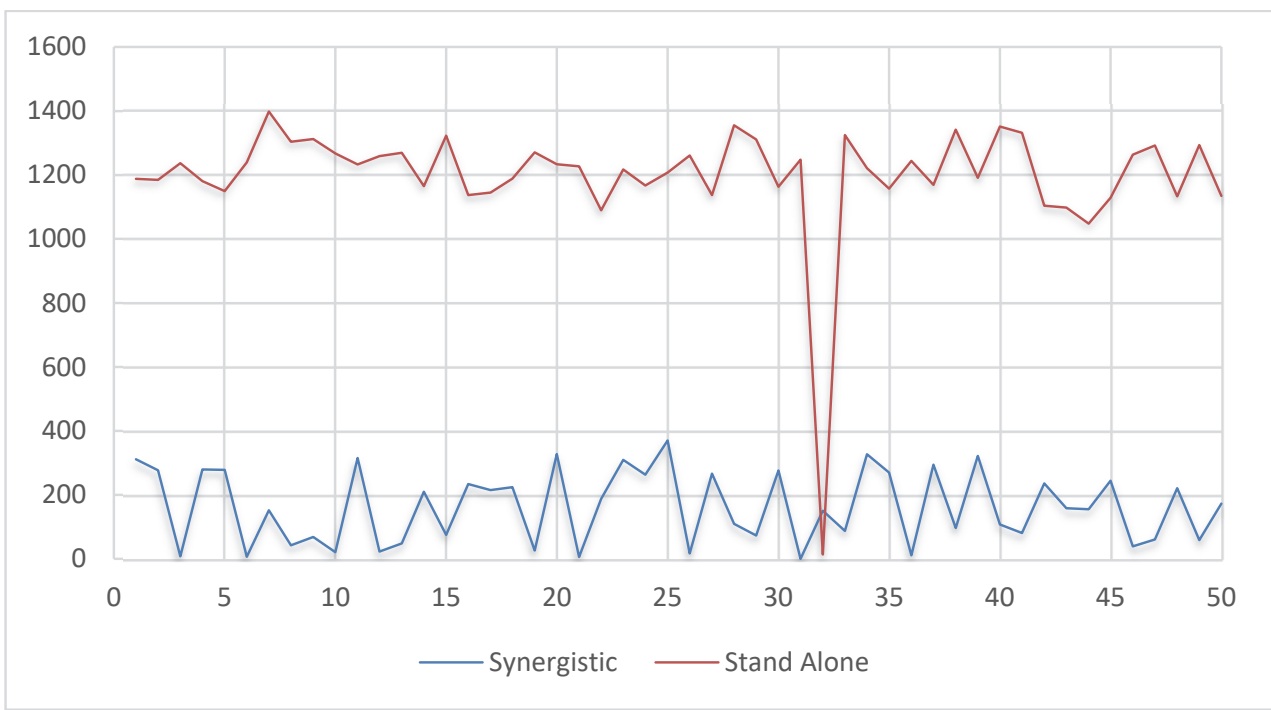

Fig. 10. Chart of the residual portfolio budget in two different cases

Fig. 11 shows the graph of projects augmented scores in both considered cases. The horizontal axis of this chart represents $P_{1}$ to $P_{9}$ projects respectively, and the vertical axis shows the augmented scores of these projects. The augmented scores for projects by calculation of synergic impacts are equal to or higher than augmented scores without consideration of synergies between projects.

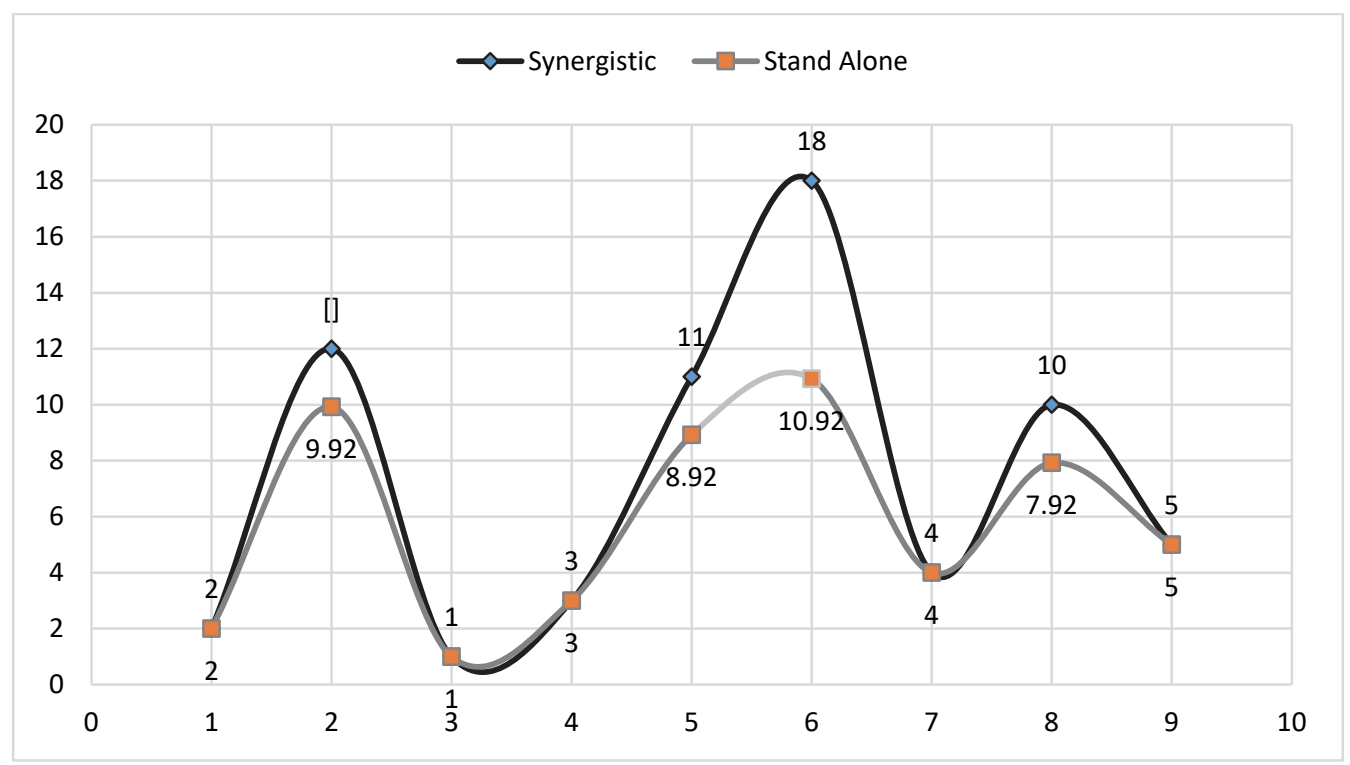

Fig. 11. Chart of projects augmented scores in two different conditions

It means that considering interdependencies among projects leads to selecting projects with more values according to selection criteria and decision-makers' preferences. In other words, although it is quite sophisticated to define, identify, and model projects interdependencies in the process of project portfolio selection, it plays an important role for the effective use of the resources of organizations and results in selecting projects more precisely considering criteria and preferences. 


\section{Conclusion}

Senior managers of projectified organizations focus on the problem of selecting a project portfolio to achieve organization strategic objectives. In the meantime, considering projects' interdependencies and their capacity to create synergies in a portfolio can play an essential role in organizational resources management and profitability. In the proposed portfolio selection framework, five types of interdependencies, including resource interdependency, technical knowledge interdependency, technical dependency, target market interdependency, and learning interdependency were considered to model synergy in a project portfolio. The resource interdependency results in cost reduction of existing resources and makes the most use of resources to run the most possible number of projects in a portfolio. The learning and technical knowledge interdependencies cause an increase in information sharing to facilitate the development and progress of projects in the same knowledge area. Technical dependency also refers to a situation in which a project is affected by the outcome of other projects, and its success/ failure depends on the success/ failure of other projects. Finally, target market interdependency aims at measuring the increase in the revenue or sale values of the results or products of interdependent projects in a market. Proposed rules and quantitative methods were applied to model and estimate the impacts of different types of projects' interdependencies. Then, using Promethee II as a multi-criteria decision-making method, the rank of each candidate project was obtained by the value of its contribution to creating synergy in a portfolio. An integer non-linear programming approach was used to solve the problem of selecting the project portfolio. Applying the proposed approach to measure projects' interdependencies results in a more efficient project portfolio. It consequently, leads to more revenue in comparison with the case in which projects' synergies were not taken into account. Furthermore, the remaining portfolio budget was reduced in comparison with the primary state.

Finally, to improve the process of modeling projects' interdependencies, it is suggested to consider various objectives such as reducing the risk or increasing portfolio efficiency in future research. Furthermore, it can be assessed as a significant step to approximate real-world cases if projects' interdependencies are modeled in any combinations (as a network) as well as paired projects for future research.

\section{References}

Almeida, A., \& Duarte, M. (2011). A multi-criteria decision model for selecting project portfolio with consideration being given to a new concept for synergies. Pesquisa Operacional, 31, 301-318.

Bai, L., Chen, H., Gao, Q., \& Luo, W. (2018). Project portfolio selection based on synergy degree of composite system. Soft Computing, 22(16), 535-45.

Bathallath, S., Smedberg, Å., \& Kjellin, H. (2016). Managing project interdependencies in IT/IS project portfolios: a review of managerial issues. International Journal of Information Systems and Project Management, 4(1), 67-82.

Behzadian, M., Kazemzadeh, R., Albadvi, A., \& Aghdasi, M. (2010). PROMETHEE: A comprehensive literature review on methodologies and applications. European Journal of Operational research, $200(1), 198-215$.

Brans, J., Vincke, P., \& Mareschal, B. (1986). How to select and how to rank projects: The PROMETHEE method. European Journal of Operational Research, 24(2), 228-38.

Georgopoulou, E., Sarafidis, Y., \& Diakoulaki, D. (1998). Design and implementation of a group DSS for sustaining renewable energies exploitation. European Journal of Operational Research, 109(2), 483-500.

Hemmatizadeh, M., \& Mohammadi, E. (2019). Project portfolio selection problem with exponential synergistic effects. Journal of Project Management, 4(3), 241-248.

Iranmanesh, S., Shakhsi-Niaei, M., \& Rastegar, H. (2019). A multi-objective optimization model for project portfolio selection considering aggregate complexity: A case study. International Journal of Optimization in Civil Engineering, 9(2), 291-311.

Killen, C., \& Kjaer, C. (2012). Understanding project interdependencies: The role of visual representation, culture, and process. International Journal of Project Management, 30(5), 554-566.

Killen, C., Krumbeck, B., Kjaer, C., \& Durant, L. (2009). Managing project interdependencies: exploring new approaches. In. Asia Pacific Expert Seminar (APES2009): Managing Projects, Programs, And Ventures, (pp. 1-8).

Kundisch, D., \& Christian, M. (2011). IT/IS project portfolio selection in the presence of project interactions-review and synthesis of the literature. Proceedings of the 10th International Conference on Wirtschaftsinformatik (pp. vol. 1, 477486). Zürich: Schweiz.

Lopes, Y., \& Almeida, A. (2015). Assessment of synergies for selecting a project portfolio in the petroleum industry based on a multi-attribute utility function. Journal of Petroleum Science and Engineering, 126, 131-140.

Mavrotas, G., Diakoulaki, D., \& Kourentzis, A. (2008). Selection among ranked projects under-segmentation, policy, and logical constraints. European Journal of Operational Research, 187(1), 177-92.

Shakhsi-Niaei, M., Torabi, S., \& Iranmanesh, S. (2011). A comprehensive framework for project selection problem under uncertainty and real-world constraints. Computer and Industrial Engineering, 61, 226-237.

Thompson, J. (1967). Organizations in action: Social science bases of administrative theory. Transaction publishers. 
(C) 2020 by the authors; licensee Growing Science, Canada. This is an open access article distributed under the terms and conditions of the Creative Commons Attribution (CC-BY) license (http://creativecommons.org/licenses/by/4.0/). 